\title{
THE FIRST RECORD OF DIPROSOPUS TETROPHTHALMUS IN THE SOUTH ATLANTIC OCEAN: THE CASE OF PRIONACE GLAUCA (ELASMOBRANCHII: CARCHARHINIFOR- MES: CARCHARHINIDAE) IN BRAZIL
}

\author{
Felipe LAMARCA ${ }^{1 *}$, Natalee RIBEIRO ${ }^{1}$, Fernando GALHEIGO ${ }^{2}$, and Marcelo VIANNA ${ }^{1}$ \\ ${ }^{1}$ Centre of Health Sciences, Institute of Biology, Federal University of Rio de Janeiro, Rio de Janeiro, RJ, Brazil \\ ${ }^{2}$ Brazilian Institute of the Environment and Renewable Natural Resources, Rio de Janeiro, RJ, Brazil
}

Lamarca F., Ribeiro N., Galheigo F., Vianna M. 2017. The first record of diprosopus tetrophthalmus in the South Atlantic Ocean: The case of Prionace glauca (Elasmobranchii: Carcharhiniformes: Carcharhinidae) in Brazil. Acta Ichthyol. Piscat. 47 (4): 385-389.

\begin{abstract}
The majority of morphological abnormalities reported for elasmobranchs are cases of bicephalia. This contribution describes the third confirmed case worldwide and the first in the South Atlantic of diprosopus tetrophthalmus (craniofacial duplication) in a foetus of blue shark, Prionace glauca (Linnaeus, 1758), from a female caught off the Brazilian coast $\left(26^{\circ} 36^{\prime} 11^{\prime \prime} \mathrm{S}, 45^{\circ} 56^{\prime} 00^{\prime \prime} \mathrm{W}\right)$ in July 2007 . The specimen is described and compared to normal specimens from the same size and to another one with similar deformities from Chile. The embryo is smaller than a normal embryo, with deformities in the skull, head muscles and curvature of the vertebral column.
\end{abstract}

Keywords: anomaly, blue shark, embryo, malformation, South Atlantic

Among cases of morphological abnormalities reported for elasmobranchs in recent years, bicephaly is the most frequent. Sans-Coma et al. (2017) reviewed 14 published cases of bicephalus and diprosopus in elasmobranchs. For the blue shark, Prionace glauca (Linnaeus, 1758), cases reported as bicephalous were described by Goto et al. (1981), Mancini et al. (2006), and Galván-Magaña et al. (2011). However, Goto et al. (1981) described two specimens with diprosopous and bicephalous features, and the case described by Mancini et al. (2006) should be classified as diprosopus. Ehemann et al. (2016) reported an additional case of bicephalia for the species. Hevia-Hormazábalet al. (2011) reported the first case of diprosopus tetrophthalmus in sharks, in a specimen of $P$. glauca caught off Chile, although according to the review by Sans-Coma et al. (2017) this would be only the third case. Okazaki et al. (1987) defined diprosopus as consisting of a single neck and body and duplication of craniofacial structures; the term tetrophthalmos is applied to an embryo with four eyes, in which the median eyes may be partially fused or separate, but share a central orbit. This contribution describes the first confirmed case of diprosopus tetrophthalmus in the South Atlantic Ocean.

Prionace glauca is a viviparous, pelagic species that is also found in coastal waters, from shallow waters up to $600 \mathrm{~m}$ depth (Compagno 1984). Prionace glauca is the main shark species caught as bycatch with longlines and gill nets (Nakano and Stevens 2008). A female embryo of $P$. glauca with a striking morphological abnormality was obtained by evisceration of a female approximately $2 \mathrm{~m}$ in total length. The female was caught off Brazil (263 $\left.6^{\prime} 11^{\prime \prime} \mathrm{S}, 45^{\circ} 56^{\prime} 00^{\prime \prime} \mathrm{W}\right)$, on July 27, 2007, from a fishing vessel operating a pelagic longline. The material was deposited in the Chondrichthyan Anatomy Collection of the Universidade do Estado do Rio de Janeiro, catalogued under number AC.UERJ 1448. The anomalous was the only embryo with malformation of the offspring. This specimen is described and compared to normal, recently fixed specimens of almost the same size but of other samples: AC.UERJ 1866.1, AC.UERJ 773.3, AC.UERJ 1448, and AC.UERJ 773.1. These numbers correspond, respectively, to normal specimens 1, 2, 3, and 4 (Table1). The differences in the measurements PG1, HDL, POR, MOL and MOW, PRN, INW, and TL (abbreviations explained in the footnote of Table 1) between the anomalous specimen and the four normal ones were calculated with a calliper (following methodology of Compagno 1984). Since this is an unusual specimen, each paired fin was measured, and the specimen was then partly dissected and the head region described using Compagno's terminology. To observe the internal morphology, the specimen was placed in a petri dish and x-rayed with the Faxitron MX-20 digital radiography system. Observation of certain structures and foramina was difficult or impossible because of the deformities in this specimen. 
Table 1

Morphometric parameters of the anomalous and normal specimens of the blue shark, Prionace glauca, caught off Brazil and off Chile expressed as a percentage of the total length (TL, in $\mathrm{mm}$ )

\begin{tabular}{|c|c|c|c|c|c|c|c|c|c|c|c|c|}
\hline \multirow[t]{2}{*}{ Parameter } & \multicolumn{2}{|c|}{ Anomalous } & \multicolumn{2}{|c|}{ Normal 1} & \multicolumn{2}{|c|}{ Normal 2} & \multicolumn{2}{|c|}{ Normal 3} & \multicolumn{2}{|c|}{ Normal 4} & \multicolumn{2}{|c|}{$\begin{array}{l}\text { Anomalous } \\
\text { Chile }\end{array}$} \\
\hline & Right & Left & Right & Left & Right & Left & Right & Left & Right & Left & Right & Left \\
\hline $\mathrm{TL}[\mathrm{mm}]$ & \multicolumn{2}{|c|}{369.0} & \multicolumn{2}{|c|}{420.0} & \multicolumn{2}{|c|}{260.0} & \multicolumn{2}{|c|}{240.0} & \multicolumn{2}{|c|}{265.0} & \multicolumn{2}{|c|}{152.0} \\
\hline DCS & \multicolumn{2}{|c|}{7.3} & \multicolumn{2}{|c|}{7.5} & \multicolumn{2}{|c|}{8.0} & \multicolumn{2}{|c|}{7.6} & \multicolumn{2}{|c|}{8.1} & & \\
\hline ACS & \multicolumn{2}{|c|}{7.1} & \multicolumn{2}{|c|}{7.2} & \multicolumn{2}{|c|}{7.7} & \multicolumn{2}{|c|}{7.5} & \multicolumn{2}{|c|}{4.4} & & \\
\hline PAS & \multicolumn{2}{|c|}{9.6} & \multicolumn{2}{|c|}{7.7} & \multicolumn{2}{|c|}{7.0} & \multicolumn{2}{|c|}{7.2} & \multicolumn{2}{|c|}{5.0} & & \\
\hline PPS & & & & & & & & & & & & \\
\hline HDL & 23.2 & 23.0 & & & & & & & & & & 51.9 \\
\hline PG1 & 17.8 & 17.6 & & & & & & & & & & 42.1 \\
\hline POR & 10.5 & 10.2 & & & & & & & & & & 22.3 \\
\hline PRN & 5.0 & 5.1 & & & & & & & & & & 9.8 \\
\hline MOL & 3.4 & 3.5 & & & & & & & & & & 7.2 \\
\hline MOW & 5.7 & 5.4 & & & & & & & & & & 12.5 \\
\hline P1B & 3.9 & 4.3 & 4.2 & 3.8 & 3.9 & 3.8 & 4.8 & 4.5 & 4.3 & 4.0 & & 6.5 \\
\hline P1L & 6.9 & 7.5 & 8.1 & 7.6 & 6.9 & 6.3 & 9.2 & 9.2 & 6.9 & 6.7 & & \\
\hline P1A & 14.8 & 16.0 & 16.7 & 16.6 & 14.7 & 15.5 & 16.7 & 15.9 & 13.2 & 14.6 & & \\
\hline P1P & 11.1 & 12.0 & 13.1 & 11.1 & 9.6 & 9.4 & 11.5 & 10.3 & 10.9 & 10.0 & & \\
\hline P2B & 2.6 & 2.7 & 4.3 & 4.0 & 2.3 & 2.5 & 4.7 & 5.0 & 3.5 & 3.4 & & 5.9 \\
\hline P2A & 5.8 & 5.6 & 5.2 & 4.7 & 5.6 & 5.3 & 4.9 & 5.0 & 4.8 & 4.3 & & 7.2 \\
\hline P2P & 4.2 & 4.3 & 3.3 & 3.2 & 3.1 & 2.7 & 3.8 & 3.2 & 3.5 & 3.6 & & \\
\hline P2I & 5.3 & 5.3 & 2.8 & 2.5 & 2.6 & 2.7 & 3.2 & 2.5 & 2.9 & 2.5 & & \\
\hline $\mathrm{P} 2 \mathrm{~L}$ & 6.9 & 7.1 & 5.6 & 5.2 & 4.7 & 4.8 & 7.2 & 6.5 & 6.2 & 6.1 & & \\
\hline ANL & & & & & & & & & & & & 6.5 \\
\hline ANB & & & & & & & & & & & & 4.6 \\
\hline ANA & & & & & & & & & & & & \\
\hline ANP & & & & & & & & & & & & 5.9 \\
\hline CDM & & & & & & & & & & & & \\
\hline CTL & & & & & & & & & & & & \\
\hline CFW & & & & & & & & & & & & \\
\hline
\end{tabular}

Values which are neither right nor left are centred; TL $=$ total length, DCS $=$ dorsal caudal-fin space, $\mathrm{ACS}=$ anal caudal-fin space, $\mathrm{PAS}=$ pelvic-fin anal-fin space, $\mathrm{PPS}=$ pectoral-fin pelvic-fin space, $\mathrm{HDL}=$ head length, $\mathrm{PG} 1=$ pre first gill length, $\mathrm{POR}=$ pre oral length, $\mathrm{PRN}=$ pre nasal length, $\mathrm{MOL}=$ mouth length, $\mathrm{MOW}=$ mouth width, $\mathrm{P} 1 \mathrm{~B}=$ pectoral-fin base, $\mathrm{P} 1 \mathrm{~L}=$ pectoral-fin length, $\mathrm{P} 1 \mathrm{~A}=$ pectoral-fin anterior margin, $\mathrm{P} 1 \mathrm{P}=$ pectoral-fin posterior margin, $\mathrm{P} 2 \mathrm{~B}=$ length of the base of pelvic-fin, $\mathrm{P} 2 \mathrm{~A}=1 \mathrm{ength}$ of the anterior margin of the pelvic-fin, $\mathrm{P} 2 \mathrm{P}=$ length of the posterior margin of pelvic-fin, $\mathrm{P} 2 \mathrm{I}=$ length of the inner margin of pelvic-fin, $\mathrm{P} 2 \mathrm{~L}=1 \mathrm{ength}$ of the pelvic-fin, $\mathrm{ANL}=$ anal-fin length, $\mathrm{ANB}=$ length of the base of the anal-fin, ANA = length of the anterior margin of the anal-fin, $\mathrm{ANP}=$ length of the posterior margin of the anal-fin, CDM = length of dorsal caudal-fin margin, CTL = length of terminal caudal-fin margin, CFW = width of the caudal-fin furca.

External morphology. The anomalous two-headed embryo showed lateral fusion, snouts and jaws with a normal external appearance, and four eyeballs and four nostrils. The median eyes were almost fused, separated only by a layer of epidermis. The single body had five gill slits on each side, and single first and second dorsal fins. The pectoral, pelvic, anal, and caudal fins had the normal pattern (Fig. 1). The distance between each snout was 52.7 $\mathrm{mm}$, and the lengths of the right and left heads differed by slightly less than $1 \mathrm{~cm}$. Compared to the normal embryos, the body measurements were consistent with the size of each specimen, including each head (Table1). The HDL, PG1, MOL, and MOW ratios were smaller than in the normal specimens.
Internal morphology. In the anomalous specimen, the following head and eye muscles were observed: levator palatequadrati, levator labii superioris, adductor mandibulae, levator hyomandibularis, levator palpebrae nictitans, rectus medialis, those that follow the obliquus inferior, as well as the pre and post-orbital processes following the direction of the deformity. The remainder of the body was normal; the deformity was mainly in the head. The single vertebral column exhibited a marked curvature in the middle of the monospondylous region (kyphosis), followed by a beginning of kyphoscoliosis, a combination of kyphosis and lateral curvature of the spine (Fig. 1d). The cranium had a deformed tripodal rostrum with an abrupt torsion. The specimen had a precerebral fossa toward the deformity. The nasal capsules were arranged in two pairs, 

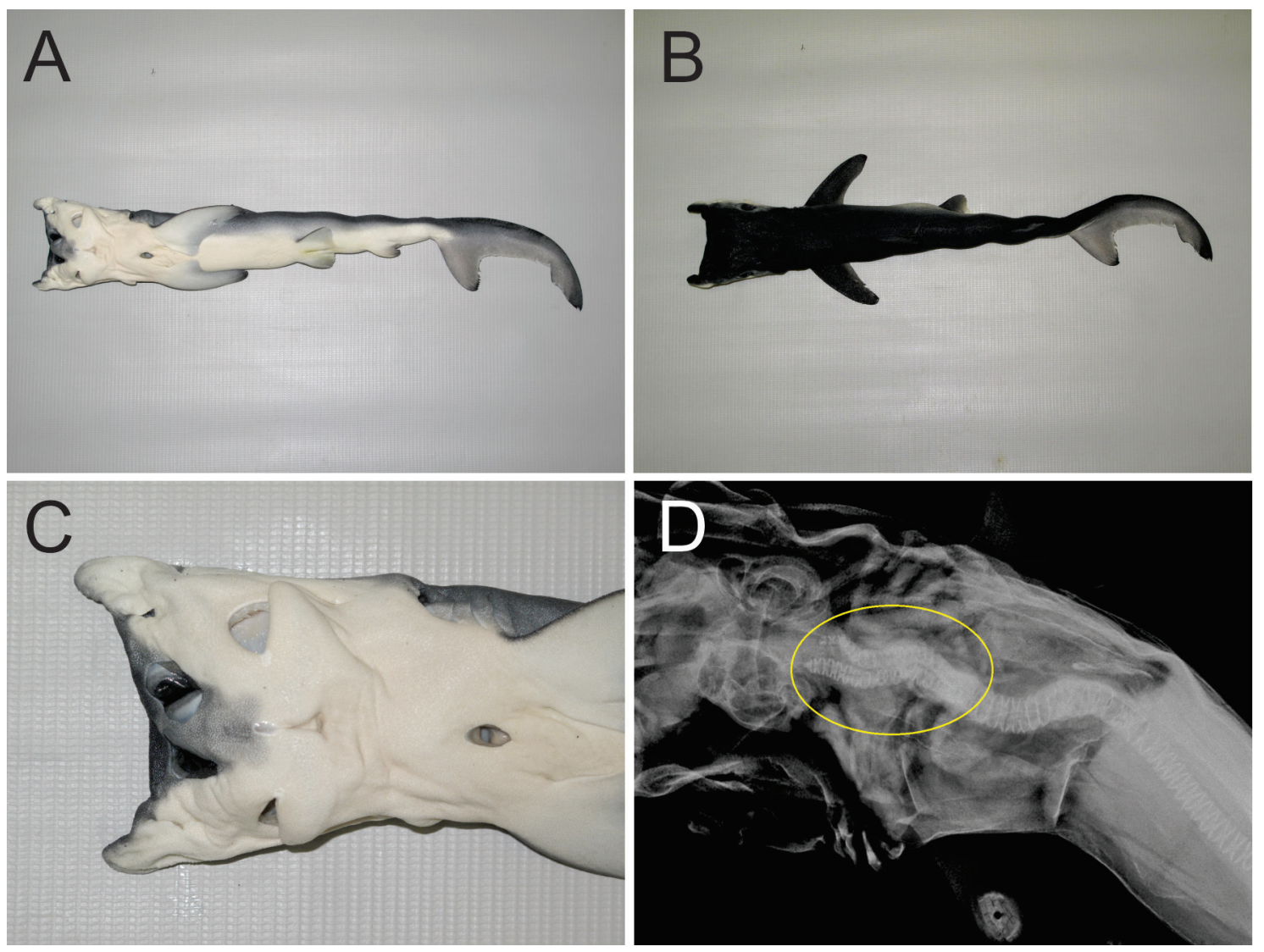

Fig. 1. Anomalous embryo of blue shark, Prionace glauca, caught off Rio de Janeiro, Brazil, AC.UERJ 1448; Whole embryo (A), dorsal view (B), ventral view (C), and dorsal view radiograph (D) (duplication and curvature of vertebral column, identified by the circle)

but were somewhat deformed. In each capsule the nasal apertures and nasal flaps were visible, but followed the direction of the anomaly. The cranial roof and anterior fontanelle of each head were normal. Posteriorly, the shared region comprised the median part of the skull roof, basal plate, and optic and occipital regions. The basal plate formed a single structure joining the orbital region of each skull. From the opposite side to the fusion, there was a normal notch next to the stapedius foramen at the midpoint of the basal plate. On the side of the fusion, the orbital wall was slightly deformed, but all the foramina of this region, which were in their normal positions, could be identified. The optical region was shared, showing normal optic capsules and the parietal fossa, the endolymphatic and perilymphatic foramina and the semicircular canals, with the hyomandibular facet on each side, ending in the occipital region. In the centre of the occipital region were two foramina magna instead of one, side by side, each connected individually with its own vertebral column, one over the other, until the connection at the beginning of the monospondylous intermediate region.

Comparing the external morphology of our anomalous specimen with the other case from Chile (HeviaHormazábal et al. 2011), it was evident that they both had two heads with lateral fusion, two snouts and four eyeballs, with the median eyes almost fused and separated only by a layer of epidermis. The jaws appeared normal externally, but in the embryo from Chile the lower jaw showed an abnormal curvature. The proportion of the measurements HDL, PG1, POR, PRN, MOL, and MOW in the anomalous head from Chile were larger than the proportions in our anomalous head, and the body measurements were slightly larger in the anomalous embryo from Chile (Table 1). According to Hevia-Hormazábal et al. (2011) this specimen "presents thoracic lordosis in the axial skeleton and helical twist in the tail", which affects the body proportions. The deformity in the column also appeared in our specimen, i.e., a sharp kyphosis in the middle monospondylic region, followed by kyphoscoliosis until the beginning of the diplospondylic caudal.

Anomalous foetuses are rarely recorded in elasmobranchs and their causes cannot be revealed (Bornatowski and Abilhoa 2009). The origins of these malformations may be associated with parasites, tumours, malnutrition, zygotic division, genetic abnormalities, pollution, overfishing, hypoxia, and hyperthermia (Mancini et al. 2006, Delpiani et al. 2011, Costa et al. 2014). This study presents the first confirmed case of diprosopus tetrophthalmus found in the Atlantic Ocean (the other case was found in the Pacific Ocean off Chile). Sans-Coma et al. (2017) suggested that two cases reported as bicephalous (Bosinceano 1934, Mancini et al. 2006) would be better considered as diprosopus. Muñoz-Osorio et al. (2013) described an anomalous specimen with a duplication 
of facial elements, which suggests a diprosopia; and the presence of two vertebral columns, which suggests bicephalia. Similar shared characteristics also occurred in two specimens of blue shark studied by Goto et al. (1981). For the anomaly described as diprosopus tetrophthalmus, this is only the second case worldwide for P. glauca and the third for sharks, because the embryo described by Mancini et al. (2006) lacks duplication in the eyes, nose, and nostril.

In Prionace glauca the small uteri and large number of embryos may cause problems in embryonic development (Galván-Magaña et al. 2011). However, on the Brazilian coast, other factors of anthropogenic origin such as contamination by chemical pollutants including heavy metals and organochlorines may affect the species. High toxicity and biomagnification of contaminants along the trophic chain have been found in blue sharks caught off Brazil (de Azevedo a Silva et al. 2007, Dias et al. 2008). The form of mercury found (methylmercury) is the most toxic and shows neurotoxicity even at low concentrations in the body, acting as a teratogenic agent that can cause disorders in the embryo even at concentrations that do not affect the mother (Choi 1991). Another problem is that P. glauca is the shark species most commonly taken by fishing vessels and is most impacted by overfishing, with declines in stocks in several parts of the world (Aires-daSilva et al. 2009). Reductions in the number of individuals by overfishing can contribute to an excessive inbreeding level, with resulting malformations in embryos. This problem of malformations further aggravates the state of the stocks, should be considered in management plans, and merits more thorough study. Dos Santos and Gadig (2014) noted that the direct influence of the high fishing mortality experienced by elasmobranchs in recent times, and the effects of marine pollutants on their embryonic malformations have not been conclusively analysed. These impacts can be assessed in the near future through more detailed studies on abnormal embryos, using embryological, genetic and ecotoxicological approaches.

\section{ACKNOWLEDGEMENTS}

We thank Marcelo R. Britto and Marcelo Soares of the Laboratory of Radiograph (MNRJ) and Ulisses L. Gomes of the Laboratory of Taxonomy of Elasmobranchs (UERJ) for their kind assistance with several aspects of this study. Janet W. Reid (JWR Associates) revised the English text.

\section{REFERENCES}

Aires-da-Silva A.M., Maunder M.N., Gallucci V.F., Kohler N.E., Hoey J.J. 2009. A spatially structured tagging model to estimate movement and fishing mortality rates for the blue shark (Prionace glauca) in the North Atlantic Ocean. Marine and Freshwater Research 60 (10): 1029-1043.

DOI: $10.1071 / \mathrm{MF} 08235$

Bornatowski H., Abilhoa V. 2009. Record of an anomalous embryo of Rhinobatos percellens (Elasmobranchii: Rhinobatidae) in the southern coast of Brazil. Marine Biodiversity Records 2: e36.

DOI: $10.1017 / \mathrm{S} 1755267209000414$
Bosinceano A. 1934. Sur un cas de monstre double incomplet chez Squalus acanthias Risso. Annales Scientifiques de l'Université de Jassy 19: 339-344.

Choi B.H. 1991. Effects of methylmercury on the developing brain. Pp. 315-337. In: Suzuki T., Imura N., Clarkson T.W. (eds.) Advances in Mercury Toxicology. Rochester Series on Environmental Toxicity. Springer, Boston, MA, USA.

DOI: $10.1007 / 978-1-4757-9071-9 \_20$

Compagno L.J.V. 1984. FAO species catalogue. Vol. 4. Sharks of the world. An annotated and illustrated catalogue of shark species known to date. Part 2Carcharhiniformes. FAO Fisheries Synopsis No. 125.

Costa M.A., Borzabadi-Farahani A., Lara-Sanchez P.A., Schweitzer D., Jacobson L., Clarke N., Hammaoudeh J., Urata M.M., Magee W.P.III. 2014. Partial craniofacial duplication: A review of the literature and case report. Journal of Cranio-MaxilloFacial Surgery 42 (4): 290-296.

DOI: $10.1016 / \mathrm{j} . j \mathrm{cms} .2013 .05 .016$

de Azevedo a Silva C.E., Azeredo A., Laison-Brito J., Torres J.P.M., Malm O. 2007. Polychlorinated biphenyls and DDT in swordfish (Xiphias gladius) and blue shark (Prionace glauca) from Brazilian coast. Chemosphere 67 (9): S48-S53

DOI: 10.1016/j.chemosphere.2006.05.089

Delpiani S.M., Deli Antoni M.Y., Barbini S.A., Figueroa D.E. 2011. First record of a dicephalic specimen of tope Galeorhinus galeus (Elasmobranchii: Triakidae). Journal of Fish Biology 78 (3): 941-944.

DOI: $10.1111 / \mathrm{J} .1095-8649.2010 .02890 . \mathrm{x}$

Dias A.C.L., Guimarães J.R.D., Malm O., Costa P.A.S. 2008. Mercúrio total em músculo de cação Prionace glauca (Linnaeus, 1758) e de espadarte Xiphias gladius Linnaeus, 1758, na costa sul-sudeste do Brasil e suas implicações para a saúde pública. [Total mercury in muscle of the shark Prionace glauca (Linnaeus, 1758) and swordfish Xiphias gladius Linnaeus, 1758, from the south-southeast coast of Brazil and the implications for public health.] Cadernos de Saúde Pública 24 (9): 2063-2070. [In Portuguese.] DOI: 10.1590/S0102-311X2008000900012

dos Santos C.H.H., Gadig O.B.F. 2014. Abnormal embryos of sharpnose sharks Rhizoprionodon porosus and Rhizoprionodon lalandii (Elasmobranchii: Carcharhinidae) from Brazilian coast, western South Atlantic. Marine Biodiversity Records 7: e55.

DOI: $10.1017 / \mathrm{S} 1755267214000554$

Ehemann N., Marín-Sanz J., Barany-Gonzáles M. 2016. Two cases of two-head shark embryos, smalleye smooth-hound Mustelus higmani and the blue shark Prionace glauca. Boletin de Investigaciones Marinas y Costeras 45 (1): 149-153.

Galván-Magaña F., Escobar-Sanchez O., CarreraFernández M. 2011. Embryonic bicephaly in the blue shark, Prionace glauca, from the Mexican Pacific Ocean. Marine Biodiversity Records 4: e1. DOI: $10.1017 / \mathrm{S} 1755267210001120$ 
Goto M., Taninuchi T., Kuga N., Iwata M. 1981. [Four dicephalous specimens of the blue shark, Prionace glauca, from Japan.] Japanese Journal of Ichthyology 28 (2): 157-165. [In Japanese.] DOI: $10.11369 / \mathrm{jji} 1950.28 .157$

Hevia-Hormazábal V., Pastén-Marambio V., Veja A. 2011. Registro de um monstruo diprósopo de tiburón azul (Prionace glauca) en Chile. International Journal of Morphology 29 (2): 509-513. DOI: $10.4067 / \mathrm{S} 0717-95022011000200034$

Mancini P.L., Casas A.L., Amorim A.F. 2006. Morphological abnormalities in a blue shark Prionace glauca (Chondrichthyes: Carcharhinidae) foetus from Southern Brazil. Journal of Fish Biology 69 (6): 18811884.

DOI: $10.1111 / \mathrm{j} .1095-8649.2006 .01238 . x$

Muñoz-Osorio L.A., Mejía-Falla P.A., Navia A.F. 2013. First record of a bicephalic embryo of smalltail shark Carcharhinus porosus. Journal of Fish Biology 82 (5): 1753-1757.

DOI: $10.1111 / \mathrm{jfb} .12102$
Nakano H., Stevens J.D. 2008. The biology and ecology of the blue shark, Prionace glauca. Pp. 140-151. In: Camhi M.D., Pikitch E.K., Babcock E.A. (eds.) Sharks of the open ocean: Biology, fisheries and conservation. Fish and Aquatic Resources Series, Vol. 13. Blackwell Publishing, Oxford, UK.

Okazaki J.R., Wilson J.L., Holmes S.M., Vandemark L.L. 1987. Diprosopus: diagnosis in utero. American Journal of Roentgenology 149 (1): 147-148. DOI: 10.2214/ajr.149.1.147

Sans-Coma V., Rodríguez C., López-Unzu M.A., Lorenzale M., Fernández B., Vida L., Durán A.C. 2017. Dicephalous v. diprosopus sharks: Record of a two-headed embryo of Galeus atlanticus and review of the literature. Journal of Fish Biology 90 (1): 283-293.

DOI: $10.1111 / \mathrm{jfb} .13175$

Received: 4 April 2017

Accepted: 21 July 2017

Published electronically: 31 December 2017 